\title{
Optimization of Sesame Roasting Parameters and Level of Ingredients for Sesame Fat Spread Production
}

\author{
Ruth Bekele Mijena \\ Food Science \& Nutrition Researcher, Ethiopian Institute of Agricultural Research, Addis Ababa, Ethiopia
}

\section{Email address:}

rutinajc@gmail.com

\section{To cite this article:}

Ruth Bekele Mijena. Optimization of Sesame Roasting Parameters and Level of Ingredients for Sesame Fat Spread Production. International Journal of Nutrition and Food Sciences. Vol. 6, No. 4, 2017, pp. 149-157. doi: 10.11648/j.jjnfs.20170604.11

Received: April 7, 2017; Accepted: April 20, 2017; Published: June 7, 2017

\begin{abstract}
The present study was carried out to standardize roasting operation for production of superior quality sesame fat spread by optimizing roasting temperature, roasting time, selecting suitable food additives and their proportion. Central composite design (CCD) was used for planning experimental design. Four factors: roasting temperature $\left(180-220^{\circ} \mathrm{C}\right)$, roasting time (10-20 min.), sugar (4-6\%) and lecithin (0.8-1.2) were evaluated with respect to overall acceptability, texture profile analysis and $\mathrm{L}^{*}, \mathrm{a}^{*}, \mathrm{~b}^{*}$ color values. The optimized roasting conditions and level of ingredients for making superior quality sesame fat spread was found to be: roasting temperature at $180^{\circ} \mathrm{C}$ for $20 \mathrm{~min}$ and incorporating $7.3 \%$ sugar, $1.2 \%$ of lecithin, $5 \%$ hydrogenated vegetable oil and $1.2 \%$ salt. The average chemical composition of sesame fat spread was found to be moisture $0.26 \%$, protein $27.0 \%$, crude fat $53.51 \%$, total carbohydrates $16.31 \%$, crude fiber $13.23 \%$, ash $3.15 \%$, phytic acid $4.64 \%$, oxalic acid $0.73 \mathrm{mg} / \mathrm{g}$. Sesame Fat Spread is categorized among nutraceutical and functional foods and healthy alternative product which can be eaten as spread on bread, biscuit sandwiches, salad dressing and in soups.
\end{abstract}

Keywords: Sesame Fat Spread, Roasting, Ingredients, Optimization, Nutritional Value

\section{Introduction}

India is the second highest producer of sesame seeds after Myanmar with annual production of 610,000 MT, followed by China and Ethiopia (FAOSTAT, 2012). Studies indicate that Ethiopia is among the six producers of Sesame seed, Linseed and Niger seed in the world [1]. In Ethiopia oilseeds cover a total of $7.63 \%$ (about 855,000 hectares) of the grain crop area and $3.83 \%$ (6.6 million quintals) of yield production to the national grain production. Niger seed, Sesame and Linseed covered $2.8 \%, 2.48 \%$ and $1.61 \%$ of grain crop area, respectively; and about $1.11 \%, 1.27 \%$ and $0.91 \%$ of the grain production [2]. Sesame seed possess very good nutritional value, superior quality fat, biologically active components and antioxidants which are health promoting. From the nutritional profile, sesame is categorized among nutraceutical and functional foods. As [3] reported the physico-chemical properties of three sesame varieties grown in Northern area of Ethiopia. Results showed that Ethiopian sesame varieties were good source in nutrients and were functional foods for human nutrition and utilization.
Many health benefit were reported such as, weight gain control, prevention against cardiovascular diseases, protection against ageing, smoothing of the skin and Alzheimer's disease and cancer inhibition [4]. Sesame oil and its lignan, sesamol are potent antioxidants and antiinflammatory agents [5]. Sesamin from sesame seeds has also been reported to possess in vivo hypo-cholesterolemic activity and suppressive attributes activity against chemically induced cancer, lipopolysaccharide and human low-density lipoprotein (LDL). Sesame in the diet can reduce the risk of heart disease [6]. Sesame contains essential fatty acids such as linoleic acid and high levels of lignans that consist of sesamin, sesaminol, sesamol, sesamolinol, or sesamolin. Sesame are very good source of B-complex vitamins such as niacin, folic acid, thiamin pyridoxine and riboflavin. Sesame seeds are incredibly rich source of many essential minerals which include calcium, iron, manganese zinc magnesium, selenium and copper in concentrated amounts. They are especially rich in mono-unsaturated fatty acid oleic acid which comprise up to $50 \%$ fatty acids [7].

Several temperature-time combinations were reported for roasting of sesame seeds during tahini and sesame paste 
production [8, 9]. But there was no studies reported on sesame fat spread production, optimization of its processing parameters and ingredients. Seed spreads have tremendous advantage for their nutritional value, simplicity and in consumer appeal. Studies on functional foods and nutraceuticals provide an opportunity to improve human health, reduce health care costs and support economic development. The development of sesame fat spread will increase the food uses of sesame and introduce consumers with alternative and a healthier, non-animal breakfast snack food. Value addition makes it easy to consume for all age groups in different food preparations. Based on significant importance of sesame seed and its products, this study focuses on optimizing processing parameters and level of ingredients for superior quality production of sesame fat spread.

\section{Materials and Methods}

\subsection{Materials}

The study was conducted in Gujarat, India. Amongst Gujarat cultivars of sesame, Guj-Til-2 was selected due to its superior quality, purity as well as popularity in domestic and international market. Mechanically hulled, auto-dry, and sortex with $99.7 \%$ purity were purchased from Virdhara International Spices Exporter, Unjha, Gujarat. Soy lecithin was purchased from Astron Chemicals India Ltd., Ahmadabad. Hydrogenated vegetable oil (zaikavanspati), salt and sugar were procured from the local market.

\subsection{Sample Preparation}

The sesame spread was prepared with varying levels of sugar 4, 6, 8 percent and lecithin $0.8,1.0$ and 1.2 percent. The salt and hydrogenated vegetable oil was added at the rate of 1.2 and 5.0 percent in all experiments. Dehulled sesame seeds were weighted, roasted, cooled, grounded and stored in refrigerator.

\subsection{Roasting and Grinding}

Roasting was performed in laboratory fluidized bed dryer using Plenum chamber (Ninjee Instruments, Ahmedabad). This consists of a truncated conical base having bottom diameter of $0.21 \mathrm{~m}$, top diameter of $0.30 \mathrm{~m}$ and $0.73 \mathrm{~m}$ cylindrical column.

Roasted sesame seeds were grounded with mixer grinder (Crompton Greaves ltd., Diva) for three minutes at low speed.

\subsection{Experimental Design for Optimization}

Central Composite Design (CCD) was employed to evaluate the combined effects of different parameters such as roasting time, roasting temperature, sugar and lecithin concentrations. The ranges and levels of the parameters were determined using the code values of $-1,0,+1$, as described by [10]. Thirty experimental variables where generated by the software where the independent variables are roasting temperature: 180- $220^{\circ} \mathrm{C}$, roasting time duration: $10-20$ minutes, sugar level: 4 $8 \%$ and lecithin level: $0.8-1.2 \%$. Dependent variables are overall acceptability (color and appearance, flavor, texture), texture profile analysis (hardness, adhesiveness and cohesiveness) and color ( $\left.\mathrm{L}^{*} \mathrm{a} * \mathrm{~b} *\right)$ values.

\subsection{Proximate Composition of Sesame Seeds and Sesame Fat Spread}

Proximate composition of sesame seeds and sesame fat spread was characterized as follows: Moisture content, total ash crude fat, crude fiber was determined according to the procedure given by [11]. While Crude protein was determined Kjeldahl method described on [12]. Total Carbohydrate was calculated using difference method. All determinations were carried out in triplicate and average values were reported.

\subsection{Determination of Anti-nutrients}

Phytic acid was determined as per the procedure given by [13]. Oxalic acid was determined as per the procedure given by [14].

\subsection{Organoleptic Evaluation}

The sensory characteristics of sesame fat spread during various experiments were determined in terms of overall acceptability (color and appearance, flavor, texture) according to the sensory evaluation technique described by [11]. Each quality attribute was assigned a score on 9 point basis, 1: dislike extremely to 9: like extremely as marked on the scorecard. The data obtained were analyzed statistically.

\subsection{Textural Profile Analysis}

The textural quality of the sesame fat spread of each treatments were determined using Double compression was applied using cylinder probe Texture Analyzer (Stable Micro Systems, U.K.; Model: TA HD plus). Sesame fat spread samples were placed in a conical sample holder and applied with a load cell of $4.5 \mathrm{~kg}$. The crosshead was set to move downward and penetrate the sesame fat spread sample. Conical perspex probe (code: HDP/SR) having 45 degree cone angle was penetrated into the sample up to a distance of $8 \mathrm{~mm}$. The conditions were: pre-test speed of cone: $1 \mathrm{~mm} / \mathrm{s}$, speed of cone while penetrating into sesame fat spread: $2 \mathrm{~mm} / \mathrm{s}$, speed of cone while withdrawal from sesame spread: $2 \mathrm{~mm} / \mathrm{s}$.

Hardness (peak force of first compression cycle), cohesiveness (ratio of positive areas of second cycle to area of first cycle) and adhesiveness (negative force area of the first byte represented the work necessary to pull the compressing plunger away from the sample) were determined. The results were recorded in terms of TPA curve of sesame spread.

\subsection{Color}

Color parameter of sesame fat spread samples was determined using Tintometre (Lovibond, Model RT850i). 
The instrument was standardized each time with a white and a black ceramic plate. In this coordinate system, the $\mathrm{L}^{*}$ value is a measure of lightness, ranging from 0 (black) to 100 (white), the* value ranges from -100 (greenness) to +100 (redness) and the $b^{*}$ value ranges from -100 (being blue) to +100 (yellowness).

\subsection{Data Analysis and Optimization of Parameters}

The Response Surface Methodology (RSM) was applied to the experimental data using, design expert version 7.0.0. Analysis of variance (ANOVA) was calculated to examine the statistical significance of the model terms. Model analysis with respect to lack-of fit test and $\mathrm{R}_{2}$ (co-efficient of determination) was done for determining adequacy of model. The co-efficient of variation (CV) was calculated to find the relative dispersion of the experimental points from the prediction. Numerical optimization technique of the DesignExpert 7.0.0 software was used for simultaneous optimization of the multiple responses. The desired goals for each factor and response were chosen.

\section{Result and Discussions}

\subsection{Chemical Characterization of Sesame Seeds}

The proximate composition and anti-nutrional factors of the sesame seed were evaluated and the results are presented on Table 1. The results crude fat, protein and ash values observed during the study are in good accordance with the results reported by $[15,16]$. Total carbohydrate and fiber content was moderately high compared to the result reported by [4]. Phytic acid content was found to be moderately high compared to the results reported by [17]. Oxalic acid was in accordance with the findings reported by [15, 18, 19]. However, some differences in the composition may be due to environmental stress, climatic conditions, geographical, cultivation and harvesting practices.

Table 1. Chemical composition of hulled sesame seeds.

\begin{tabular}{ll}
\hline Composition & Mean value \pm S.D \\
\hline Moisture\% & $2.27 \pm 0.35$ \\
Protein $\%$ & $27.0 \pm 0.6$ \\
Crude fat $\%$ & $52.22 \pm 0.18$ \\
Total Carbohydrates\% & 15.11 \\
Crude fiber\% $\%$ & $13.23 \pm 2.4$ \\
Ash\% & $3.4 \pm 0.27$ \\
Phytic acid\% & $7.52 \pm 1.24$ \\
Oxalic acid $(\mathrm{mg} / \mathrm{g})$ & $0.80 \pm 0.44$ \\
\hline
\end{tabular}

\subsection{Optimization of Roasting Conditions and Ingredients}

The experiments for optimization for roasting conditions and ingredients were conducted as per the experimental design and responses are shown in Table 2 and Table 3.

Table 2. Variables and responses of experimental design for overall acceptability.

\begin{tabular}{|c|c|c|c|c|c|}
\hline No. & Roasting Temp ${ }^{\circ} \mathrm{C}$ & Roasting Time min & Sugar \% & Lecithin, \% & Overall acceptability, (1-9) \\
\hline 1 & 200 & 15 & 10 & 1.00 & 7.14 \\
\hline 2 & 220 & 20 & 4 & 1.20 & 6.00 \\
\hline 3 & 200 & 15 & 6 & 1.00 & 7.286 \\
\hline 4 & 220 & 10 & 8 & 0.80 & 6.77 \\
\hline 5 & 180 & 10 & 8 & 0.80 & 6.29 \\
\hline 6 & 200 & 15 & 6 & 0.60 & 6.96 \\
\hline 7 & 180 & 10 & 4 & 1.20 & 6.57 \\
\hline 8 & 160 & 15 & 6 & 1.00 & 6.14 \\
\hline 9 & 220 & 10 & 8 & 1.20 & 6.71 \\
\hline 10 & 180 & 20 & 8 & 0.80 & 7.43 \\
\hline 11 & 220 & 20 & 4 & 0.80 & 6.57 \\
\hline 12 & 200 & 15 & 6 & 1.40 & 6.74 \\
\hline 13 & 240 & 15 & 6 & 1.00 & 6.43 \\
\hline 14 & 220 & 10 & 4 & 1.20 & 6.43 \\
\hline 15 & 180 & 10 & 4 & 0.80 & 6.68 \\
\hline 16 & 180 & 20 & 8 & 1.20 & 7.00 \\
\hline 17 & 200 & 15 & 6 & 1.00 & 7.43 \\
\hline 18 & 220 & 20 & 8 & 0.80 & 6.71 \\
\hline 19 & 200 & 25 & 6 & 1.00 & 7.29 \\
\hline 20 & 200 & 15 & 6 & 1.00 & 7.29 \\
\hline 21 & 200 & 15 & 6 & 1.00 & 7.14 \\
\hline 22 & 180 & 10 & 8 & 1.20 & 6.43 \\
\hline 23 & 220 & 10 & 4 & 0.80 & 7.00 \\
\hline 24 & 200 & 15 & 6 & 1.00 & 7.57 \\
\hline 25 & 200 & 15 & 2 & 1.00 & 6.43 \\
\hline 26 & 180 & 20 & 4 & 1.20 & 6.29 \\
\hline 27 & 200 & 15 & 6 & 1.00 & 7.57 \\
\hline 28 & 180 & 20 & 4 & 0.80 & 6.71 \\
\hline 29 & 220 & 20 & 8 & 1.20 & 6.57 \\
\hline 30 & 200 & 5 & 6 & 1.00 & 6.42 \\
\hline
\end{tabular}


Table 3. Variables and responses of experimental design for texture profile and color values.

\begin{tabular}{|c|c|c|c|c|c|c|c|c|c|c|}
\hline No. & $\begin{array}{l}\text { Roasting } \\
\text { Temp }^{\circ} \mathrm{C}\end{array}$ & $\begin{array}{l}\text { Roasting } \\
\text { Time min }\end{array}$ & Sugar $\%$ & Lecithin,\% & $\begin{array}{l}\text { Hardness, } \\
\text { g }\end{array}$ & $\begin{array}{l}\text { Adhesiveness, } \\
\text { g-sec }\end{array}$ & Cohesiveness & $\begin{array}{l}\text { Color } \\
\text { value } L^{*}\end{array}$ & $\begin{array}{l}\text { Color } \\
\text { value } a^{*}\end{array}$ & $\begin{array}{l}\text { Color } \\
\text { value b* }\end{array}$ \\
\hline 1 & 200 & 15 & 10 & 1.00 & 243.788 & -207.442 & 0.528 & 53.90 & 3.63 & 22.20 \\
\hline 2 & 220 & 20 & 4 & 1.20 & 177.856 & -166.866 & 0.606 & 47.28 & 7.52 & 28.34 \\
\hline 4 & 220 & 10 & 8 & 0.80 & 290.49 & -207.539 & 0.478 & 49.72 & 6.29 & 25.77 \\
\hline 5 & 180 & 10 & 8 & 0.80 & 221.173 & -168.903 & 0.474 & 56.46 & 1.95 & 18.18 \\
\hline 6 & 200 & 15 & 6 & 0.60 & 237.901 & -153.508 & 0.494 & 54.49 & 3.87 & 21.67 \\
\hline 8 & 160 & 15 & 6 & 1.00 & 197.794 & -195.962 & 0.585 & 56.35 & 1.61 & 17.35 \\
\hline 9 & 220 & 10 & 8 & 1.20 & 184.417 & -196.058 & 0.662 & 48.97 & 6.30 & 26.68 \\
\hline 10 & 180 & 20 & 8 & 0.80 & 168.512 & -130.888 & 0.577 & 55.88 & 2.21 & 19.15 \\
\hline 11 & 220 & 20 & 4 & 0.80 & 151.723 & -116.404 & 0.482 & 47.58 & 7.42 & 28.07 \\
\hline 12 & 200 & 15 & 6 & 1.40 & 227.144 & -170.766 & 0.626 & 54.52 & 3.83 & 21.63 \\
\hline 13 & 240 & 15 & 6 & 1.00 & 181.069 & -168.439 & 0.643 & 45.90 & 10.58 & 28.48 \\
\hline 14 & 220 & 10 & 4 & 1.20 & 149.801 & -147.956 & 0.692 & 48.58 & 5.93 & 26.87 \\
\hline 15 & 180 & 10 & 4 & 0.80 & 212.676 & -149.795 & 0.479 & 56.08 & 1.94 & 18.38 \\
\hline 17 & 200 & 15 & 6 & 1.00 & 197.544 & -199.337 & 0.524 & 53.97 & 3.32 & 21.59 \\
\hline 18 & 220 & 20 & 8 & 0.80 & 158.54 & -147.408 & 0.594 & 47.88 & 7.14 & 27.37 \\
\hline 19 & 200 & 25 & 6 & 1.00 & 178.592 & -148.19 & 0.621 & 51.86 & 4.85 & 24.75 \\
\hline 20 & 200 & 15 & 6 & 1.00 & 239.738 & -183.166 & 0.551 & 57.68 & 3.37 & 23.26 \\
\hline 21 & 200 & 15 & 6 & 1.00 & 223.24 & -174.232 & 0.508 & 57.53 & 3.37 & 23.45 \\
\hline 22 & 180 & 10 & 8 & 1.20 & 172.15 & -156.653 & 0.584 & 59.78 & 1.89 & 19.40 \\
\hline 23 & 220 & 10 & 4 & 0.80 & 248.356 & -172.476 & 0.499 & 51.67 & 6.23 & 29.54 \\
\hline 24 & 200 & 15 & 6 & 1.00 & 218.127 & -186.359 & 0.565 & 57.57 & 3.39 & 23.22 \\
\hline 25 & 200 & 15 & 2 & 1.00 & 151.518 & -148.852 & 0.578 & 57.46 & 3.94 & 23.65 \\
\hline 26 & 180 & 20 & 4 & 1.20 & 219.436 & -203.389 & 0.678 & 58.27 & 2.73 & 21.51 \\
\hline 27 & 200 & 15 & 6 & 1.00 & 191.609 & -163.302 & 0.543 & 57.68 & 3.29 & 23.36 \\
\hline 28 & 180 & 20 & 4 & 0.80 & 145.632 & -136.735 & 0.587 & 58.38 & 2.76 & 21.53 \\
\hline 29 & 220 & 20 & 8 & 1.20 & 163.073 & -171.747 & 0.652 & 51.73 & 7.33 & 30.99 \\
\hline 30 & 200 & 5 & 6 & 1.00 & 168.898 & -143.856 & 0.550 & 59.57 & 3.21 & 19.85 \\
\hline
\end{tabular}

\subsubsection{Effect of Roasting and Level of Ingredients on Overall Acceptability of Sesame Fat Spread}

Analysis of variances results indicated that among linear effects, sugar had highly significant effect on overall acceptability $(\mathrm{p}<0.01)$. Lecithin and roasting time had significant effect at $5 \%$ and $10 \%$ on overall acceptability. Interaction effect of roasting temperature with roasting time as well as roasting time with sugar level was found to be significant at $1 \%$. Quadratic effect of all variables had significant effect on overall acceptability $(\mathrm{p}<0.01)$. The quadratic model developed in the coded form of process variables is:

Equation (1) Overall acceptability $=+7.38-2.202 \mathrm{E}-003 *$

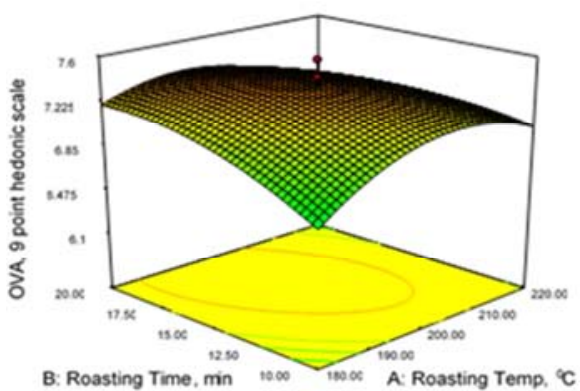

(a)
$\mathrm{A}+0.088 * \mathrm{~B}+0.13 * \mathrm{C}-0.11 * \mathrm{D}-0.16 * \mathrm{~A} * \mathrm{~B}-7.589 \mathrm{E}-$ $003 * \mathrm{~A} * \mathrm{C}-0.032 * \mathrm{~A} * \mathrm{D}+0.16 * \mathrm{~B} * \mathrm{C} 0.061 * \mathrm{~B} * \mathrm{D}$ $+0.075 * \mathrm{C} * \mathrm{D}-0.28 * \mathrm{~A}^{2}-0.14 * \mathrm{~B}^{2}-0.16 * \mathrm{C}^{2}-0.14 * \mathrm{D}^{2}$

$\mathrm{A}=$ Roasting temperature, $\mathrm{B}=$ Roasting time, $\mathrm{C}=$ Sugar, $\mathrm{D}=$ Lecithin

The effect of roasting temperature and time on overall acceptability is shown in Figure 1. It can be seen roasting time and roasting temperature up to $200^{\circ} \mathrm{C}$ increased overall acceptability. This may be due to the increase in flavor of sesame at high roasting conditions. It was reported that roasting temperatures below $200^{\circ} \mathrm{C}$ with longer roasting time resulted in higher overall acceptability of similar product [20].

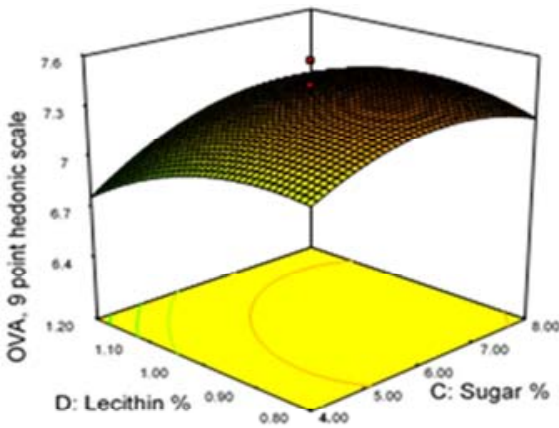

(b)

Figure 1. Effect of roasting conditions (a) and ingredients (b) on overall acceptability of sesame fat spread. 
From the RSM graph it can be observed that overall acceptability increased with increasing level of sugar. It was reported sesame paste with high level of sweetener had highest overall acceptability score [21]. Another study [22] showed that highest blend of pine honey with sesame paste had highest overall acceptability. They also mentioned that it might be due to a dilution effect of the sweetness on the oiliness of sesame paste enhancing the sensory acceptance of product. Overall acceptability decreased with the increase of lecithin above $1 \%$. This may be due to the reason that lecithin above $1 \%$ decreases the viscosity of sesame fat spread. It was reported overall acceptability was rated higher by addition of $1 \%$ emulsifier for similar product $[23,24]$.

\subsubsection{Effect of Roasting Conditions and Ingredients on Texture Profile of Sesame Fat Spread}

\section{(i). Effect on Hardness}

ANOVA results showed that among linear effects, roasting time had significant on hardness at 5\%. Roasting temperature, lecithin and sugar were found to be nonsignificant on hardness at $5 \%$. Interaction effect of roasting temperature with lecithin as well as roasting time with lecithin was found to be significant at 5\%. Quadratic effect of roasting time had significant effect on hardness of sesame spread $(\mathrm{p}<0.05)$.

Final equation in terms of coded factors:

Equation (2) Hardness $=+214.69-3.16 * \mathrm{~A}-11.84 * \mathrm{~B}$ $+9.51 * \mathrm{C}-5.20 * \mathrm{D}-8.77 * \mathrm{~A} * \mathrm{~B}+5.87 * \mathrm{~A} * \mathrm{C}-15.28 * \mathrm{~A} *$ $\mathrm{D}-2.18 * \mathrm{~B} * \mathrm{C}+24.57 * \mathrm{~B} * \mathrm{D}-7.31 * \mathrm{C} * \mathrm{D}-7.18 * \mathrm{~A}^{2}-$ $11.10 * \mathrm{~B}^{2}-5.12 * \mathrm{C}^{2}+3.60 * \mathrm{D}^{2}$

$\mathrm{A}=$ Roasting temperature, $\mathrm{B}=$ Roasting time, $\mathrm{C}=$ Sugar, $\mathrm{D}=$ Lecithin

Figure 2 shows that increase in roasting time above $15 \mathrm{~min}$ decreased hardness and increase in lecithin decreased hardness. This may be due to the longer time duration of roasting which may increase the fracture-ability of the roasted sesame seeds. It was reported that decrease in hardness with increase of roasting time [24]. Reference [25] also reported similar results for pistachio kernels. As in [23]

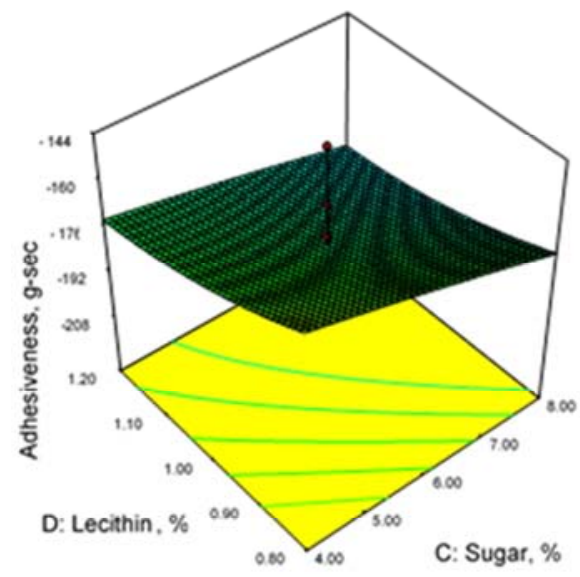

(a) reported the reduction of hardness with increase of emulsifier.

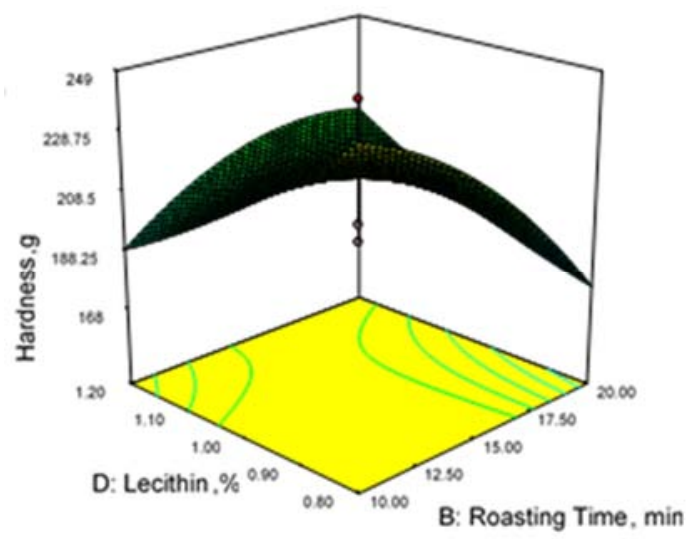

Figure 2. Effect of lecithin and roasting time on hardness of sesame fat spread.

\section{(ii). Effect on Adhesiveness}

ANOVA results showed that among linear effects, sugar and lecithin had highly significant effect on adhesiveness $(p<0.01)$. Interaction effect of roasting time with lecithin was found to be significant at $1 \%$. Other interaction effects and quadratic effect were observed to be non-significant. Final equation in terms of coded factors:

Equation (3) Adhesiveness $=-175.12+2.22 * \mathrm{~A}+2.89 * \mathrm{~B}-$ $10.44 * \mathrm{C}-9.39 * \mathrm{D}+10.32 * \mathrm{~A} * \mathrm{~B} 6.55 * \mathrm{~A} * \mathrm{C}+7.08 * \mathrm{~A} *$ $\mathrm{D}+3.37 * \mathrm{~B} * \mathrm{C}-16.03 * \mathrm{~B} * \mathrm{D}+1.58 * \mathrm{C} * \mathrm{D}-1.53 * \mathrm{~B}^{2}-$ $0.52 * \mathrm{C}^{2}+3.48 * \mathrm{D}^{2}$

$\mathrm{A}=$ Roasting temperature, $\mathrm{B}=$ Roasting time, $\mathrm{C}=$ Sugar, $\mathrm{D}=$ Lecithin

Figure 3 shows that increase in lecithin and sugar decreased adhesiveness which is a desired property. This may be due to the reason that lecithin and sugar enhance consistency of the product. It was reported effect of emulsifier for similar product [23]. As reported by [26] the increase in sucrose increased consistency of similar product.

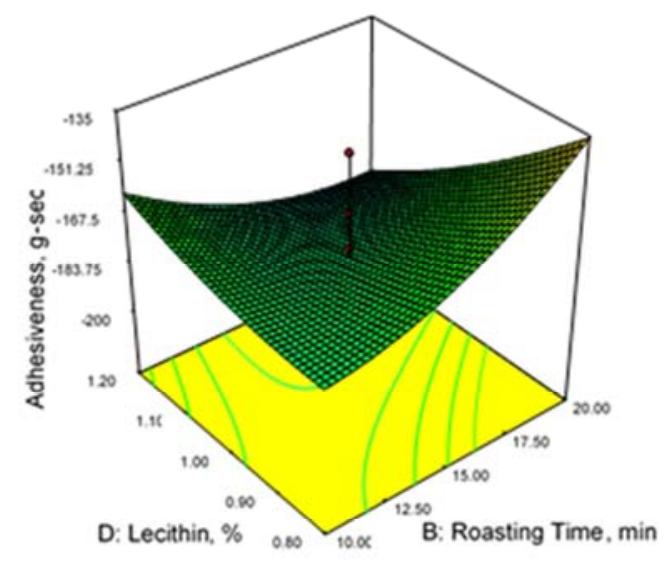

(b)

Figure 3. Effect of lecithin and sugar (a) \& Lecithin and roasting time (b) on adhesiveness of sesame fat spread. 


\section{(iii). Effect on Cohesiveness}

Analysis of variances results showed that among linear effects, lecithin had highly significant effect on cohesiveness $(\mathrm{p}<0.01)$. Roasting time had significant effect on cohesiveness at $1 \%$ whereas; roasting temperature and sugar were found to be non-significant on cohesiveness. Interaction effects of roasting time and temperature were observed to be significant at $1 \%$. Quadratic effect of roasting temperature had significant effect on cohesiveness $(\mathrm{p}<0.01)$.

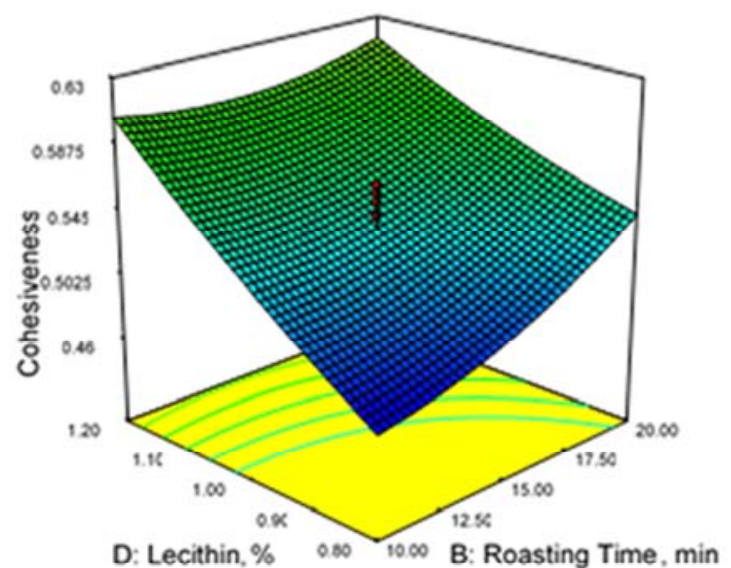

(a)
Final equation in terms of coded factors:

Equation (4) Cohesiveness $=+0.54+5.315 \mathrm{E}-003 * \mathrm{~A}$ $+0.021 * \mathrm{~B}-1.864 \mathrm{E}-003 * \mathrm{C}+0.052 * \mathrm{D}-0.022 * \mathrm{~A} * \mathrm{~B}$ $+9.739 \mathrm{E}-003 * \mathrm{~A} * \mathrm{C}+8.562 \mathrm{E}-003 * \mathrm{~A} * \mathrm{D}+0.014 * \mathrm{~B} * \mathrm{C}-$ $0.016 * \mathrm{~B} * \mathrm{D}-6.011 \mathrm{E}-003 * \mathrm{C} * \mathrm{D}+0.019 * \mathrm{~A}^{2}+0.012 * \mathrm{~B}^{2}$ $+3.726 \mathrm{E}-003 * \mathrm{C}^{2}+5.486 \mathrm{E}-003 * \mathrm{D}^{2}$

$\mathrm{A}=$ Roasting temperature, $\mathrm{B}=$ Roasting time, $\mathrm{C}=$ Sugar, $\mathrm{D}=$ Lecithin

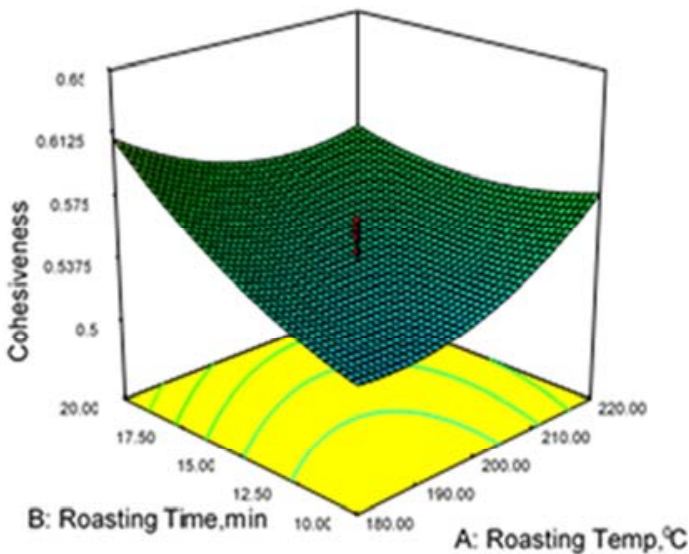

(b)

Figure 4. Effect of lecithin and roasting time (a) \& roasting time and temperature (b) on cohesiveness of sesame fat spread.

Figure 4 shows increasing lecithin increased cohesiveness. These phenomena may be due to the ability of lecithin to emulsify the product effectively. Reference [23] reported cohesiveness increased with addition of emulsifier for similar product. Increase in roasting temperature and time increased cohesiveness of the product. This may be due to the reason that the more and the longer roasting causes uniform size of ground product.

\subsubsection{Effect of Roasting Conditions and Ingredients on Color of Sesame Fat Spread}

\section{(i). Effect on Color Value L*}

The results showed that among linear effects, roasting temperature had highly significant effect $(\mathrm{p}<0.01)$ on $\mathrm{L}^{*}$ value of color. Interaction effects were observed to be nonsignificant. Quadratic effect of roasting temperature had significant effect $\mathrm{L}^{*}$ value of color at $1 \%$. Final equation in terms of coded factors:

Equation (5) Color value $\mathrm{L}^{*}=+56.46-3.46 * \mathrm{~A}-0.84 * \mathrm{~B}$ $-0.21 * \mathrm{C}+0.073 * \mathrm{D}-0.27 * \mathrm{~A} * \mathrm{~B}+0.26 * \mathrm{~A} * \mathrm{C}-0.14 * \mathrm{~A} *$ $\mathrm{D}-0.24 * \mathrm{~B} * \mathrm{C}+0.23 * \mathrm{~B} * \mathrm{D}+0.61 * \mathrm{C} * \mathrm{D}-1.53 * \mathrm{~A}^{2}-0.39 *$ $\mathrm{B}^{2}-0.39 * \mathrm{C}^{2}-0.69 * \mathrm{D}^{2}$

$\mathrm{A}=$ Roasting temperature, $\mathrm{B}=$ Roasting time, $\mathrm{C}=$ Sugar, $\mathrm{D}=$ Lecithin

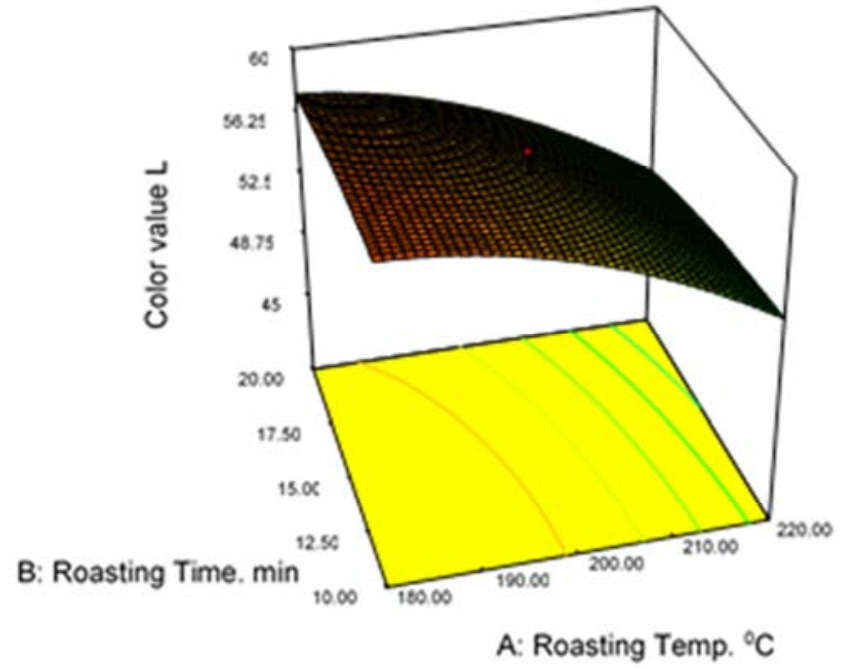

Figure 5. Effect of roasting time and temperature on color value $L^{*}$.

Figure 5 shows that increasing roasting temperature above $200^{\circ} \mathrm{C}$ decreased $\mathrm{L}$ value of color. This may be due to the fact that over roasting may cause darker color to seeds. While roasting temperature and roasting time had high significant effect on color values of $a^{*}$ and $b^{*}$. As in mentioned in [19] there was a declining in the L-values (darkening) of seeds at higher roasting temperatures and they mentioned that the low-moisture content, denaturation of proteins, and the concentrated amount of oil particles embedded in protein matrix could be reasons of color variation during roasting of 
sesame. Similar results were observed by [27].

\section{(ii). Effect on Color Value a*}

Analysis of variances results showed that among linear effects, roasting temperature and roasting time had highly significant effect on $a^{*}$ value of color $(p<0.01)$. Sugar had significant effect at $1 \%$. Interaction effect of roasting temperature with roasting time as well as roasting time with sugar level was found to be significant at $1 \%$ level. Other interaction effects were observed to be non-significant. Quadratic effect of all variables had significant effect on $a^{*}$ value of color at $1 \%$ level.

Final equation in terms of coded factors:

Equation (6) Color value a* $=+3.31+2.25 * \mathrm{~A}+0.43 * \mathrm{~B}-$ $0.067 * \mathrm{C}+0.015 * \mathrm{D}+0.14 * \mathrm{~A} * \mathrm{~B}+0.057 * \mathrm{~A} * \mathrm{C}-0.027 * \mathrm{~A} *$ $\mathrm{D}-0.088 * \mathrm{~B} * \mathrm{C}+0.047 * \mathrm{~B} * \mathrm{D}+0.032 * \mathrm{C} * \mathrm{D}+0.71 *$ $\mathrm{A}^{2}+0.19 * \mathrm{~B}^{2}+0.13 * \mathrm{C}^{2}+0.15 * \mathrm{D}^{2}$

$\mathrm{A}=$ Roasting temperature, $\mathrm{B}=$ Roasting time, $\mathrm{C}=$ Sugar, $\mathrm{D}=$ Lecithin

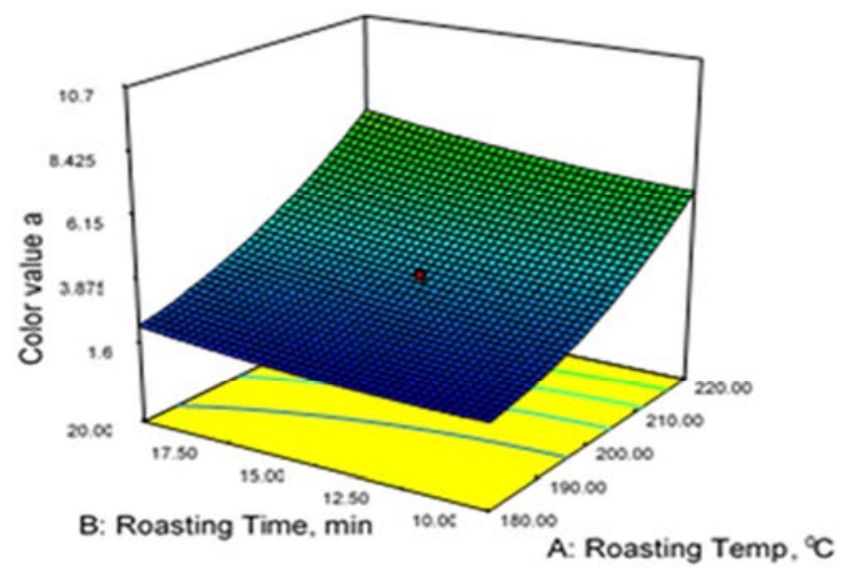

Figure 6. Effect of roasting temperature and roasting time on color value a* of sesame fat spread.

Figure 6 shows that color value $\mathrm{a}^{*}$ increased with increase of temperature as well as increase of roasting time. Reference [27] described that the higher roasting temperature and longer exposure time resulted in the greater a-value and darker color for similar product. Reference [15] also reported similar result that increase in the $a^{*}$ value was due to formation of brown pigments through the non-enzymatic browning and phospholipids degradation.

\section{(iii). Effect on Color Value of $b^{*}$}

Analysis of variance results showed that among linear effects, roasting temperature and roasting time duration had highly significant effect on $b$ value of color $(p<0.01)$. Sugar and lecithin did not show significant effect on color value $b^{*}$. Interaction effects were observed to be non-significant. Quadratic effects of all variables were non-significant effect at $1 \%$ level.

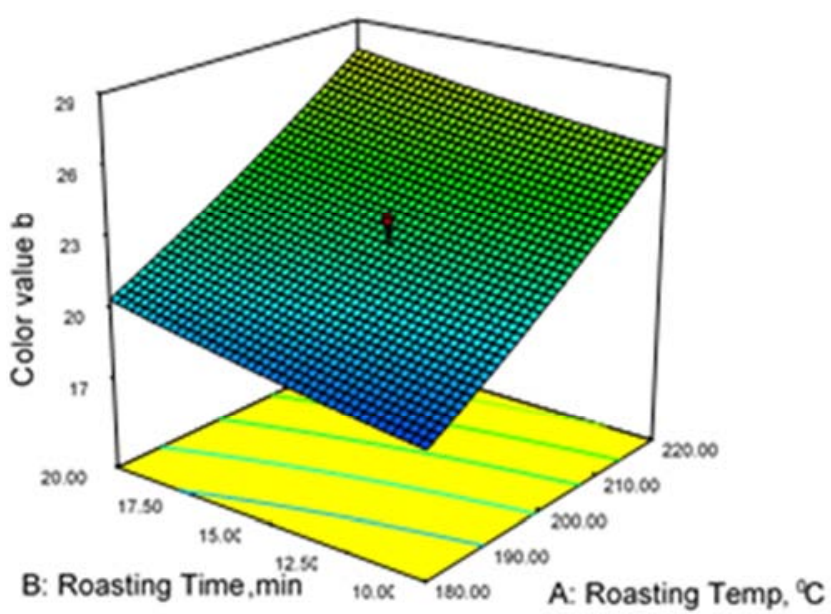

Figure 7. Effect of roasting temperature and roasting time on color value $b^{*}$ of sesame fat spread.

From the RSM graph it can be observed that color value $b^{*}$ increases with increase of temperature and of roasting time. This may be due to high roasting temperatures and longer exposure time. Similar trend was observed by $[25,28]$.

\subsection{Optimization of Sesame Fat Spread}

The optimum quality characteristics of sesame fat spread were determined by overall acceptability, texture profile analysis and color values. The optimized conditions were decided based on the following parameters: maximum overall acceptability, maximum hardness and minimum adhesiveness and $L^{*}$ value $53-58, a *$ value $1-4, b *$ value $19-24$.

Table 4. Optimized combinations.

\begin{tabular}{ll}
\hline Parameters & Optimal values \\
\hline Roasting temperature ${ }^{\circ} \mathrm{C}$ & 180.0 \\
Roasting time, min & 20.0 \\
Sugar $\%$ & 7.3 \\
Lecithin\% & 1.2 \\
\hline
\end{tabular}

\subsection{Chemical Charactersization of Sesame Fat Spread}

The chemical composition of sesame fat spread i.e. moisture, total ash, protein, crude fat, crude fiber, carbohydrate, phytic acid and oxalic acid are presented in Table 5. Fat, protein, moisture results are in good accordance with to the result reported by [29, 30]. Phytic acid reported was found be in good accordance to the results reported by [17]. Oxalic acid observed was in accordance with the findings reported by $[18,19]$ for processed seed.

Table 5. Chemical composition of sesame fat spread.

\begin{tabular}{ll}
\hline Composition & Mean value \pm S.D \\
\hline Moisture\% & $0.26 \pm 0.03$ \\
Protein\% $\%$ & $27.0 \pm 0.6$ \\
Crude fat\% & $53.51 \pm 2.43$ \\
Total Carbohydrates\% & 16.31 \\
Crude fiber\% & $13.23 \pm 1.4$ \\
Ash\% & $3.15 \pm 0.02$ \\
Phytic acid\% & $4.64 \pm 2.32$ \\
Oxalic acid (mg/g) & $0.73 \pm 0.22$ \\
\hline
\end{tabular}


In sesame spread, phytic acid was reduced by $38 \%$ while oxalic acid was reduced by $9 \%$ compared to the sesame seeds. Similar reduction in phytic acid was reported by other workers $[17,18,19]$. Reduction of phytic acid and oxalic acid may not be due to destruction of the compound but may rather be due to its ability to complex with protein and minerals [31].

\section{Conclusion}

There are many studies which was done on sesame and teheni/ sesame paste, but there was no product developed as sesame fat spread. This study developed sesame fat spread by optimizing the roasting parameters and the level of the ingredients to offer nutritious and healthy alternative food product to the consumers that is similar to peanut butter. It is shown that different of roasting temperatures and roasting durations, Sugar level and lecithin level affected the overall acceptability (color and appearance, flavor, texture), texture profile and $\mathrm{L}^{*}, \mathrm{a}^{*}, \mathrm{~b}^{*}$ values of color. Hydrogenated vegetable oil of $5.0 \%$ and $1.2 \%$ of salt were found to stabilize the texture and improved the flavor. The product was found to have overall acceptability 7.7, hardness 220.29 g, adhesiveness 200.39, color value $L^{*} 55.33, a^{*} 2.74$ and $b^{* 21.37}$. The optimized parameters were: $180^{\circ} \mathrm{C}$ temperature, $20 \mathrm{~min}$ of roasting, $7.3 \%$ sugar and $1.2 \%$ lecithin. The average chemical composition of sesame fat spread was moisture $0.26 \%$, protein $27.0 \%$, crude fat $53.51 \%$, total carbohydrates $16.31 \%$, crude fiber $13.23 \%$, ash $3.15 \%$, phytic acid $4.64 \%$, oxalic acid $0.73 \mathrm{mg} / \mathrm{g}$. Sesame Fat Spread is categorized among nutraceutical and functional foods and healthy alternative product which can be eaten as spread on bread, biscuit sandwiches, salad dressing and in soups.

\section{Acknowledgements}

The author sincerely acknowledges African Union for Indo-African Scholarship program for funding this study. A multitude thanks goes to Dr. R. V. Prasad, Er. Amee Ravani and Dr. D. C. Joshi at College of Food Processing Technology and Bio-Energy, AAU, Gujarat, India. A very special thanks goes to the staff members of Agricultural Quality and Nutrition Research Laboratory Directorates of Ethiopian Institute of Agricultural Research.

\section{References}

[1] Wijnands, J., Biersteker, J. and Van Loo E. N. (2009). Oilseeds Business Opportunities in Ethiopia. Public Private Partnership, The Hague, 1-60.

[2] Central Statistical Authority (CSA). (2009). Federal Democratic Republic Ethiopia: Central Statistics Agency.

[3] Zebib, H., Bultosa, G. and Abera, S. (2015) Physico-Chemical Properties of Sesame (Sesamum indicumL.) Varieties Grown in Northern Area, Ethiopia. Agricultural Sciences, 6, 238-246.

[4] Bhide, P. G., West, W. C., Fry, K. R. and Frost, D. O. (1994).
An immunocytochemical marker for hamster retinal ganglion cells. Journal of Neurocytology. 23: 167-177.

[5] Hsu D. Z., Su S. B., Chien S. P., Chiang P. J., Li Y. H. and Lo Y. J. (2005). Effect of sesame oil on oxidativestress-associated renal injury in endotoxemic rats: involvement of nitric oxide and proinflammatory cytokines. Shock. 24: 276-280.

[6] Kang, M. H., Kawai, Y., Naito, M. and Osawa T. (1999). Dietary defatted sesame flour decreases susceptibility to oxidative stress in hypercholesterolemic rabbits. J Nutr. 129: 1885-1890.

[7] Katsuzaki, H., Kawakishi, S. and Osawa, T. (1994). Sesaminol glucosides in sesame seeds. Phytochemistry. 35: 773-776.

[8] Kahyaoglu, T. and Kaya, S. (2006). Modeling of moisture, color and texture changes in sesame seeds during the conventional roasting. Journal of Food Engineering. 75: (2), 167-177.

[9] Ozcan, M., and Akgu"1, A. (1994). Physical and chemical properties and fatty acid composition of tahin (sesame paste). Gıda, 19: 411-416 (in Turkish).

[10] Das, H. (2005). Handbook of Food Processing Operations Analysis, Asian Books Private Limited.

[11] Ranganna, M. S. (1986). Handbook of Analysis and Quality Control for Fruits and Vegetables Products, McGraw Hill Publishing Co. Ltd., New Delhi.

[12] AOAC., 1996. Official Methods of Analysis of the Association of official Analytical Chemistry. Inc. Gaithersburg, Maryland.

[13] Lucas, G. M. and Markakas, (1975). Phytic acid and other phosphorus compounds of bean (Phaseolus vulgaris) J. Agric. Edu. Chem., 23: 13-15.

[14] Sanchez-Alonso, F. and M. Lachica, (1987). Seasonal trends in the elemental content of plum leaves. Commun. Soil Sci. Plant Anal., 18: 31-44.

[15] Makinde, F. M. and Akinoso, R. (2014). Comparison between the nutritional qualities of flour obtained from raw, roasted and fermented sesame (Sesamum indicum L.) seed grown in Nigeria. Acta Sci. Pol. Technol. Aliment. 13: (3), 309-319.

[16] Elleuch, M., Besbes, S., Roiseux, O., Blecker, C. and Attia, H. (2007). Quality characteristics of sesame seeds and byproducts. Journal of Food Chemistry. 103: 641-650.

[17] Embaby, H. E. S. (2011). Effect of heat treatments on certain antinutrients and In vitro protein digestibility of peanut and sesame seeds. Food Science and Technology Research. 17:(1), 31-38.

[18] Makinde, F. M. and Akinoso, R. (2013). Nutrient Composition and effect of processing treatments on anti-nutritional factors of Nigerian sesame (Sesamum indicum Linn) cultivars. International Food Research Journal. 20, 2293-2300.

[19] Adegunwa M. O., Adebowale A. A, Solano E. O. (2012) Effect of thermal processing on the Biochemical composition, antinutritional factors and functional properties of beniseeds (Sesamum indicum) flour. Am J Biochem Mol Biol. 2 (3): $175-182$.

[20] Dhamsaniya, N. K. and Patel, N. C. 2013. Standardizing peanut roasting process of peanut butter production. International Journal of Engineering Research \& Technology. 2: (6), 714-717. 
[21] Alpaslan, M. and Hayta, M. (2002). Rheological and sensory properties of pekmaz (grape molasses)/tahin (sesame paste) blends. Journal of Food Engineering, 54: 89-93.

[22] Akbulut, M., Saricoban, C. and Ozcan, M. M. (2012). Determination of rheological behavior, emulsion stability, color, and sensory of sesame pastes (tahin) blended with pine honey. Food and Bioprocess Technology. 5: (5), 1832-1839.

[23] Elleuch, M., Bedigian, D., Maazoun, B., Besbes, S., Blecker, C. and Attia, H. (2014). Improving halva quality with dietary fibers of sesame seed coats and date pulp, enriched with emulsifier. Food Chemistry. 145: 765-771.

[24] Shakerardekani, A., Karim, R., Ghazali, H. M., \& Chin, N. L. (2011). Effect of roasting conditions on hardness, moisture content and colour of pistachio kernels. Moisture Content and Colour of Pistachio Kernels.

[25] Kahyaoglu, T. and Kaya, S. (2006). Modeling of moisture, color and texture changes in sesame seeds during the conventional roasting. Journal of Food Engineering. 75: (2), 167-177.

[26] Emadzadeh, B., Razavi, S. M. A., Hashemi, M., Mahallati, M. N. and Farhoosh, R. (2011). Optimization of fat replacers and sweetener levels to formulate reduced-calorie pistachio butter: a response surface methodology. International Journal of Nuts and Related Sciences. 2: (4), 37-54.

[27] Ozdemir, M., and Devres, O. (2000). Kinetics of color changes of hazelnuts during roasting. Journal of Food Engineering. 44: 31-38.

[28] Moss, J. R., Otten, L. 1989. A relationship between colour development and moisture content during roasting of peanut Canadian Institute of Food Science and Technology Journal. 22 pp. 34-39.

[29] Çiftci, D., Kahyaoglu T., Kapucu S. and Kaya S. (2008). Colloidal stability and rheological properties of sesame paste. Journal Food Engineering. 87: (3), 428-435.

[30] Abu-Jdayil, B. (2003). Modelling the time-dependent rheological behavior of semi-solid foodstuffs. Journal of Food Engineering. 57: (1), 97-102.

[31] Bishnoi, S., Khetrpaul, N. and R. K. Yadav, 1994. Effect of domestic processing and cooking methods on phytic acid and polyphenol contents of pea cultivars (Pissm sativum). Plant Foods for Human Nutrition 45: 381- 388. 